\title{
Perbandingan Pengetahuan Remaja Tentang Dampak Kehamilan pada Remaja Sebelum dan Sesudah Diberikan Pendidikan Kesehatan Reproduksi Melalui Media Video
}

\author{
Firda Thursyana ${ }^{1}$, Puspa Sari ${ }^{2}$, Merry Wijaya ${ }^{3}$ \\ ${ }^{I}$ Program Studi D4 Kebidanan, Fakultas Kedokteran, Universitas Padjadjaran, Bandung, 40215, Indonesia \\ ${ }^{2,3}$ Departemen Ilmu Kesehatan Masyarakat, Fakultas Kedokteran Universitas Padjadjaran, Bandung
}

\begin{tabular}{l}
\hline ARTICLE INFORMATION \\
\hline Article Trace \\
Submission: January, 10, 2019 \\
Final Revision: March 01, 2019 \\
Available online: April 20, 2019 \\
\hline
\end{tabular}

\section{Kata kunci :}

Dampak kehamilan remaja, media video, pendidikan kesehatan, pengetahuan

Key Word :

Impact of teen pregnancy, video media, health education, knowledge

Contact:

firdathursyana@gmail.com

\begin{abstract}
A B S T R A K
Berbagai masalah kesehatan seksual dan reproduksi terjadi dikalangan remaja. Masalah yang cukup tinggi pada remaja saat ini adalah kehamilan pada remaja. Berdasarkan penelitian kehamilan remaja di Kabupaten Sumedang berhubungan dengan pola asuh orang tua, pengaruh teman dan pacaran, serta pajanan media informasi. Penelitian ini bertujuan untuk membandingkan pengetahuan remaja sebelum dan sesudah diberikan pendidikan kesehatan tentang dampak kehamilan pada remaja melalui media video. Metode yang digunakan dalam penelitian ini adalah metode penelitian quasi eksperimental dengan konsep one group pre-test dan post-test design. Pengembangannya dengan cara melakukan satu kali pengukuran sebelum dan sesudah diberikan pendidikan kesehatan. Pengambilan sampel dilakukan menggunakan teknik stratified random sampling. Jumlah sampel yang digunakan sebanyak 52 responden usia 17-19 tahun sebagai siswi SMAN Jatinangor. Instrumen penelitian menggunakan kuesioner dengan mengambil data langsung. Penelitian ini menggunakan analisis univariat dan bivariat dengan uji normalitas kolmogorov-smirnov dan uji Wilcoxon. Waktu penelitian pada tanggal 28 Juli 2016. Hasil penelitian ini adalah bahwa sebelum pendidikan kesehatan $71,2 \%$ responden berpengetahuan cukup dan sesudah pendidikan kesehatan berubah menjadi $94,2 \%$ responden memiliki pengetahuan baik. Terdapat perbedaan pengetahuan remaja sebelum dan sesudah diberikan pendidikan kesehatan melalui video tentang dampak kehamilan remaja dengan $p$ value 0,000 . Simpulan penelitian ini adalah pengetahuan remaja sesudah diberikan pendidikan kesehatan melalui media video lebih tinggi dibandingkan sebelum diberikan pendidikan kesehatan melalui media video.
\end{abstract}

\begin{abstract}
A B S T R A C T
A wide range of sexual and reproductive health problems occur among adolescents. The issue is high on teenage pregnancy on nowadays are teenagers. Based on studies of teenage pregnancies in Sumedang-related parenting parents, the influence of friends and dating, as well as media exposure information. This study aims to compare the knowledge of teenagers before and after the given health education about the impact of pregnancy on teens through the medium of video. The methods used in this research was quasi experimental research method with the concept of one group pre test and post test design. Development by way of doing a one time measurement before and after health education was given. Sampling is done using a stratified random sampling technique. The number of samples that used as many as 52 respondents ages 17-19 years as a schoolgirl SMAN Jatinangor. Instrument research using questionnaires with retrieving the data directly. This research using univariate analysis and bivariat with kolmogorov-smirnov test for normality and Wilcoxon test. Research time on July 28, 2016. The results of this research is that before health education $71.2 \%$ of respondents knowledgeable enough and after health education changed
\end{abstract}


to $94.2 \%$ respondents have knowledge well. There is a difference of knowledge teenagers before and after health education is provided through video on the impacts of teenage pregnancies with $p$ value 0.000 . Summary of the research is given after the teenager's knowledge of health education through the medium of video is higher than before given health education through the medium of video.

\section{PENDAHULUAN}

Masa remaja merupakan peralihan dari masa kanak-kanak ke masa dewasa dengan melibatkan perubahan berbagai aspek seperti biologis, psikologis, dan sosial budaya. Batasan usia remaja menurut World Heath Organzation (WHO) adalah 10 sampai 19 tahun (WHO, 2015). Secara fisik, remaja mengalami kematangan organ reproduksi, secara kognitif dan intelektual semakin berkembang dan secara psikososial remaja cenderung untuk membentuk peer group serta mulai adanya ketertarikan terhadap lawan jenis (BPS, 2013).

Menurut data Riset Kesehatan Dasar (Riskesdas) 2013, proporsi kehamilan pada usia 15-19 tahun adalah 1,97\%, dengan jumlah presentase kehamilan remaja di perkotaan sebesar $1,28 \%$ dan di pedesaan $2,71 \%$, jumlah presentase kehamilan remaja di pedesaan lebih tinggi dibanding perkotaan (Departemen Kesehatan, 2013).

Kehamilan pranikah remaja di Kabupaten Sumedang sebesar 40,5\%. Penelitian ini menemukan usia remaja ketika hamil pertama pada usia 13-19 tahun. Berdasarkan penelitian tersebut kehamilan remaja di Kabupaten Sumedang berhubungan dengan pola asuh orang tua, pengaruh teman dan pacaran, serta pajanan media informasi (Omarsari, 2008).

Kehamilan remaja dapat berdampak negatif pada kesehatan remaja dan bayinya, juga berdampak terhadap sosial dan ekonomi. Kehamilan berusia muda atau remaja antara lain berisiko kelahiran premature, berat badan bayi lahir rendah (BBLR), perdarahan postpartum, yang dapat meningkatkan kematian ibu dan bayi (Gibbs, 2008).

Kehamilan remaja dapat berdampak negatif pada kesehatan remaja dan bayinya, juga berdampak terhadap sosial dan ekonomi. Kehamilan berusia muda atau remaja antara lain berisiko kelahiran premature, berat badan bayi lahir rendah (BBLR), perdarahan postpartum, yang dapat meningkatkan kematian ibu dan bayi. Persalinan pada ibu dibawah usia 20 tahun memiliki kontribusi dalam tingginya angka kematian neonatal, bayi dan balita. Menurut SDKI 2012 angka neonatal, postnatal, bayi dan balita pada ibu yang berusia kurang dari 20 tahun lebih tinggi dibandingkan pada usia 20-39 tahun (Gyan, 2013).

Data tersebut sesuai dengan penelitian yang dilakukan di berbagai negara bahwa kehamilan pada usia kurang dari 20 tahun dapat mengakibatkan masalah kesehatan pada ibu dan bayinya. Masalah pada ibu yaitu anemia, eklampsi yang berdampak pada peningkatan morbiditas dan mortalitas ibu. Dampak pada bayinya yaitu BBLR (Berat Badan Lahir Rendah), prematur, kematian bayi, stillbirth (Gibbs, 2015). Selain itu, sebuah penelitian di Ghana menyebutkan bahwa kehamilan pranikah remaja akan mengakibatkan dropped out dari sekolah yang mengakibatkan timbulnya perasaan malu, depresi, frustasi, dengan demikian remaja yang mengalami gangguan kesehatan reproduksi menjadi tidak sehat fisik, mental dan sosial (Gyan, 2013).

Sebuah penelitian di Amerika Serikat menyebutkan bahwa pendidikan seks harus diajarkan sejak dini baik di keluarga maupun di sekolah disesuaikan dengan usianya. Pendidikan seks ini dilakukan untuk mencegah terjadi kehamilan pranikah remaja, aborsi dan masalah kesehatan perempuan maupun pada bayinya. Hal tersebut sesuai dengan penelitian di Italy bahwa pendidikan kesehatan reproduksi dapat meningkatakan pengetahuan remaja sehingga mencegah terjadinya kehamilan pada remaja (Stanger, 2011; Nyong et.al, 2011).

Supaya remaja bisa tumbuh sehat dan bisa berkontribusi dalam pembangunan, remaja perlu dan berhak mendapat informasi serta layanan kesehatan yang komprehensif hal tersebut termuat dalam rekomendasi International Conference on Population and Development (ICPD) tahun 1994. Hingga saat ini, pemenuhan hak tersebut tersebut terus diupayakan oleh 
Negara-negara anggota Perserikatan Bangsabangsa (PBB) termasuk Indonesia (Hidayat, 2007).

Berdasarkan studi pendahuluan di SMAN Jatinangor hasil wawancara peneliti dengan 20 siswa, 14 siswi mengatakan kurang mengetahui tentang penyebab dan dampak kehamilan pada remaja. Hal tersebut dikarenakan belum mendapatkan pendidikan kesehatan secara khusus mengenai kesehatan reproduksi khususnya dampak kehamilan pada remaja di sekolahnya. Siswa juga mengatakan belum ada ekstrakurikuler mengenai kesehatan reproduksi remaja, maka dari itu mereka berharap mendapatkan pendidikan kesehatan tentang kesehatan reproduksi remaja khususnya tentang dampak kehamilan pada remaja.

Penelitian ini bertujuan untuk membandingkan pengetahuan remaja tentang dampak kehamilan pada remaja sebelum dan sesudah diberikan pendidikan kesehatan reproduksi melalui media video

\section{METODE PENELITIAN}

Penelitian ini menggunakan metode penelitian quasi eksperimental dengan konsep kontrol one group pre-test dan post-test design. Peneliti membandingkan pengetahuan sebelum dan setelah diberikan pendidikan kesehatan dengan cara pengukuran pre-test dan post-test pada satu kelompok. Penelitian ini dilaksanakan pada bulan Juli 2016. Populasi dalam penelitian ini adalah seluruh siswi SMAN Jatinangor kelas XI dan XII berjumlah 444 orang. Teknik pengambilan sampel yang digunakan dalam penelitian ini adalah metode proportionate stratified random sampling yaitu pengambilan sampel yang digunakan pada kelompok homogen atau berstrata secara proporsional. Jumlah sampel yang akan diteliti adalah 52 orang

Cara pengumpulan data pada penelitian ini adalah dengan cara memberikan kuesioner pretest dan post-test. Analisis data pada penelitian ini menggunakan analisis univariat untuk melihat presentase dari variabel yang diteliti dan analisis bivariat untuk mengetahui ada tidaknya perbedaan yang signifikan antara pengetahuan sebelum dan sesudah diberikan pendidikan kesehatan tentang dampak kehamilan remaja.

\section{HASIL DAN PEMBAHASAN}

Tabel 1: Distribusi Pengetahuan Remaja Mengenai Dampak Kehamilan Remaja Sebelum Diberikan Pendidikan Kesehatan

\begin{tabular}{llll}
\hline \multirow{2}{*}{ Kategori } & \multicolumn{2}{l}{$\begin{array}{l}\text { Pengetahuan } \\
\text { Pendidikan Kesehatan }\end{array}$} & $\begin{array}{c}\text { Desudahikan } \\
\end{array}$ \\
\cline { 2 - 3 } & $\mathbf{n}$ & $\mathbf{\%}$ \\
\hline Baik & 49 & 94,2 & \\
Cukup & 3 & 5,8 & \\
Kurang & 0 & 0 & \\
\hline Total & 52 & 100 \\
\hline
\end{tabular}

Berdasarkan table diatas pengetahuan remaja sebelum diberikan pendidikan kesehatan melalui video sebagian besar memiliki pengetahuan cukup dengan jumlah responden 37 orang $(71,2 \%)$ dan terdapat responden dengan pengetahuan kurang sebanyak 5 orang $(9,6 \%)$.

\section{Tabel 4.2 Distribusi Pengetahuan Remaja Mengenai Dampak Kehamilan Remaja Sesudah Diberikan Pendidikan Kesehatan}

\begin{tabular}{llll}
\hline \multirow{2}{*}{ Kategori } & \multicolumn{1}{l}{$\begin{array}{l}\text { Pengetahuan } \\
\text { Pendidikan Kesehatan }\end{array}$} & Debelum \\
\cline { 2 - 3 } & $\mathbf{n}$ & \% \\
\hline Baik & 10 & 19,2 \\
Cukup & 37 & 71,2 \\
Kurang & 5 & 9,6 \\
\hline Total & 52 & 100 \\
\hline
\end{tabular}

Berdasarkan table tersebut pengetahuan remaja sesudah diberikan pendidikan kesehatan melalui video berpengetahuan baik menjadi 49 orang $(94,2 \%)$ dan cukup 3 orang $(5,8 \%)$ serta tidak ada responden dengan pengetahuan kurang. 
Tabel 4.3 Distribusi Silang Pengetahuan Remaja Mengenai Dampak Kehamilan Remaja Sebelum dan Sesudah Diberikan Pendidikan Kesehatan

\begin{tabular}{|c|c|c|c|c|c|c|c|c|}
\hline \multirow{3}{*}{$\begin{array}{l}\text { Pengetahuan } \\
\text { Sebelum }\end{array}$} & \multicolumn{6}{|c|}{ Pengetahuan Sesudah } & \multirow{2}{*}{\multicolumn{2}{|c|}{ Total }} \\
\hline & \multicolumn{2}{|c|}{ Baik } & \multicolumn{2}{|c|}{ Cukup } & \multicolumn{2}{|c|}{ Kurang } & & \\
\hline & $\mathbf{n}$ & $\%$ & $\mathbf{n}$ & $\%$ & $\mathbf{n}$ & $\%$ & $\mathbf{n}$ & $\%$ \\
\hline Baik & 10 & 19,2 & 0 & 0 & 0 & 0 & 10 & 19,2 \\
\hline Cukup & 36 & 69,2 & 1 & 2 & 0 & 0 & 37 & 71,2 \\
\hline Kurang & 3 & 5,8 & 2 & 3,8 & 0 & 0 & 5 & 9,6 \\
\hline Total & 49 & 94,2 & 3 & 5,8 & 0 & 0 & 52 & 100 \\
\hline
\end{tabular}

Berdasarkan table 4.3 menunjukkan hasil bahwa pengetahuan responden sebagian besar berubah dari sebelum pendidikan kesehatan cukup dan sesudah pendidikan kesehatan baik yaitu sebanyak 35 orang $(69,2 \%)$ dan pengetahuan responden sebelum pendidikan kesehatan kurang menjadi baik yaitu 3 orang $(5,8 \%)$ serta pengetahuan responden sebelum pendidikan kesehatan kurang menjadi cukup yaitu 2 orang $(3,8 \%)$.

Tabel 4.4 Perbandingan Pengetahuan Remaja Tentang Dampak Kehamilan Remaja Sebelum dan Sesudah Diberikan Pendidikan Kesehatan Melalui Video

\begin{tabular}{llllll}
\hline Data & $\mathbf{n}$ & Mean & Median & Z hitung & p value \\
\hline Pre test & \multirow{2}{*}{52} & 77.02 & 75 & -6.113 & 0.000 \\
Post test & & 91.92 & 95 & & \\
\hline
\end{tabular}

Berdasarkan table 4.4 diketahui bahwa terdapat perbedaan pengetahuan remaja sebelum dan sesudah diberikan pendidikan kesehatan melalui video tentang dampak kehamilan remaja karena $p$ value $(0,000)<0,05$ atau nilai $Z$ hitung $(6,113)>Z$ table $(1,96)$. Pengetahuan remaja tentang dampak kehamilan remaja sesudah diberikan pendidikan kesehatan melalui video lebih tinggi (95) dibandingkan sebelum diberikan pendidikan kesehatan melalui video yaitu 75 .

\section{Pengetahuan Remaja Sebelum Diberikan Pendidikan Kesehatan Melalui Video}

Berdasarkan hasil penelitian, diketahui bahwa pengetahuan remaja/siswi SMAN Jatinangor sebelum diberikan pendidikan kesehatan melalui video memiliki pengetahuan yang cukup mengenai dampak kehamilan remaja dengan presentase sebesar $71,2 \%$ serta terdapat $9,6 \%$ dengan pengetahuan kurang. Hal ini disebabkan karena siswi tersebut belum mendapatkan informasi mengenai dampak kehamilan remaja.
Hasil penelitian ini sejalan dengan hasil penelitian yang dilakukan di SMA Bali pada tahun 2016 bahwa pengetahuan remaja SMA tentang kehamilan ini tergolong ke dalam kategori cukup sebesar 52,\% dan tingkat pengetahuan kurang 3,9\%. Pada penelitian ini menunjukkn bahwa perlu memberikan informasi seperti promosi kesehatan masyarakat kelompok remaja yang aktif tetap diperlukan sebagai langkah pencegahan primer terhadap masalah kesehatan reproduksi (Umairah). Hasil penelitian ini juga sejalan dengan hasil penelitian yang dilakukan di SMK Palembang pada tahun 2014, bahwa pengetahuan remaja SMK mengenai dampak kehamilan usia dini termasuk ke dalam kategori cukup sebanyak $53.8 \%$ dan pengetahuan kurang 9,4\% (Asmarani, 2014).

Hasil ini menunjukkan pengetahuan remaja mengenai dampak kehamilan remaja tergolong dalam kategori cukup, dikarenakan belum mendapatkan pengetahuan yang lebih jelas mengenai dampak kehamilan remaja. Tingkat 
pengetahuan remaja dipengaruhi oleh pemberian informasi secara data sebesar $31,51 \%$ (Notoarmojo, 2007). Maka dari itu, diperlukan pemberian informasi melalui pendidikan kesehatan kepada remaja mengenai dampak kehamilan remaja supaya dapat meningkatkan pengetahuan remaja.

\section{Pengetahuan Remaja Sesudah Diberikan Pendidikan Kesehatan Melalui Video}

Berdasarkan hasil penelitian, diketahui bahwa pengetahuan remaja/siswi SMAN Jatinangor sesudah diberikan pendidikan kesehatan melalui video memiliki pegetahuan baik sebesar 94,2\% dan tidak ada siswi dengan pengetahuan kurang. Hal ini sesuai dengan penelitian yang dilakukan di Amerika Serikat oleh Brandon Brown (2014) bahwa media audio visual seperti video dapat mempermudah peningkatan pengetahuan seseorang (Brown, 2014). Hal ini disebabkan karena remaja telah mendapatkan informasi secara langsung mengenai dampak kehamilan remaja dengan cara pendidikan kesehatan melalui video. Menurut teori bahwa informasi dapat mempengaruhi pengetahuan. Informasi yang diberikan kepada siswi melalui media video mengenai perkembangan remaja, dampak kehamilan remaja, pencegahan kehamilan remaja, dan kejadian kehamilan remaja di Indonesia.

Menurut teori, informasi mengenai data ini dapat mempengaruhi pengetahuan seseorang sebesar 31,51\% (Notoatmojo, 2007). Kelebihan media video yaitu menunjukkan kembali gerakangerakan, pesan-pesan dengan menggunakan efek tertentu sehingga dapat memperkokoh proses pembelajaran dan informasi yang disampaikan mudah dipahami dan diingat oleh responden sehingga dapat meningkatkan pengetahuan remaja mengenai dampak kehamilan remaja, karena menurut teori pemberian informasi dan pendidikan dapat memengaruhi tingkat pengetahuan seseorang (Fitria, 2014)

\section{Pengetahuan Remaja Sebelum dan Sesudah Diberikan Pendidikan Kesehatan Melalui Media Video}

Setelah dianalisis menggunakan uji hipotesis kategorik berpasangan melalui uji Kolmogorov didapatkan nilai median pre-test 75 dan post-test 95, sehingga pengetahuan remaja setelah diberikan pendidikan kesehatan melalui video lebih tinggi dibandingkan sebelum diberikan pendidikan kesehatan melalui video. Serta nilai $Z$ hitung $6.113>Z$ table $(1,96)$ yang menyatakan bahwa adanya peningkatan pengetahuan pada remaja sebelum dan sesudah diberikan pendidikan kesehatan melalui video tentang dampak kehamilan remaja (Ambarwat dkk, 2014. Hasil uji Wicoxon menyatakan $\mathrm{p}$ value 0,000 yang artinya terdapat perbandingan yang bermakna antara sebelum dan sesudah diberikan pendidikan kesehatan melalui video. Hal ini dapat disebabkan karena metode dan media yang digunakan lebih efektif dalam penyampaian informasi bagi remaja.

Hasil penelitian ini sejalan dengan penelitian Ambarwati(2014) yang melakukan pendidikan kesehatan menggunakan media video dengan metode pre-test dan post-test dengan hasil penelitian terdapat peningkatan pengetahuan yang signifikan dan penggunaan media video lebih efektif untuk memberikan pendidikan kesehatan. Hasil penelitian ini juga sejalan dengan hasil penelitian Supriadi dkk yang dilakukan pada tahun 2014 yang menyimpulkan bahwa terdapat peningkatan pengetahuan menjadi baik sebesar $80,8 \%$ setelah diberikan pendidikan kesehatan melalui media video dibandingkan sebelum diberikan pendidikan kesehatan melalui media video (Supriadi dkk, 2014).

Hasil ini sesuai dengan teori bahwa media video lebih efektif sebagai media pendidikan kesehatan karena media video mengandung unsur audio dan visual, sehingga memberikan infromasi yang jelas terhadap pesan yang disampaikan. Pesan yang disampaikan dapat berupa fakta, bersifat informatif edukatif maupun instruksional. Maka dari itu, dalam penelitian ini pengetahuan remaja sesudah diberikan pendidikan kesehatan melalui media video lebih tinggi sebesar 94,2\% dibandingkan sebelum diberikan pendidikan kesehatan melalui media video. Ketika remaja sudah mengerti diharapkan remaja mampu mengiplementasikan terhadap sikap dan perilakunya untuk mencegah terjadinya kehamilan pada remaja.

\section{KESIMPULAN}

Dari hasil penelitian yang telah dilakukan di SMAN Jatinangor dapat disimpulkan bahwa: 
1) Pengetahuan remaja sebelum pendidikan kesehatan melalui video sebagian besar cukup dengan presentase $71,2 \%$ dan kurang 9,6\%.

2) Pengetahuan remaja sesudah diberikan pendidikan kesehatan melalui video sebagian besar berpengetahuan baik dengan presentase $94,2 \%$ dan tidak terdapat pengetahuan dengan kategori kurang.

3) Pengetahuan remaja sesudah diberikan pendidikan kesehatan melalui media video lebih tinggi 94,2\% dan tidak ada yang berpengetahuan kurang dibandingkan sebelum diberikan pendidikan kesehatan melalui media video $71,2 \%$ dan kurang 9,6\%. Terdapat perbandingan pengetahuan sebelum dan sesudah pendidikan kesehatan yang secara statistik bermakna dengan nilai $\mathrm{p}$ value $0,000<0,05$.

\section{DAFTAR PUSTAKA}

Ambarwati, dkk. Media Leaflet, Video dan Pengetahuan Siswa SD Tentang Bahaya Merokok. Jurnal Kesehatan Masyarakat. Surakarta. Kemas 10 (1) 7-13.2014.

Ayu Asmarani. Hubungan Tingkat Pengetahuan dan Sikap Remaja Putri Tentang Dampak Kehamilan Usia Dini SMK Assanadiyah tahun 2014. Palembang. 2014.

Badan Pusat Statistik, BKKBN, Kementerian Kesehatan, Measure DHS, ICF International. Laporan Pendahuluan SDKI 2012 dan KRR;2013.

Brown, Brandon. Public Health Education Using Pop Culture and Media. Public Health, Departement of Population Health and Disease Prevention, University of California. USA.Vol. 0210 November 2014.

Departemen Kesehatan RI .Riset Kesehatan Dasar 2013.Jakarta;2013:164. http://www.depkes.go.id/resources/downlo
ad/general/Hasil\%20Riskesdas\%202013.p

$\underline{\mathrm{df}}$

Gibbs, CM, Wendt A, Peters S, Hogue CJ. The Impact of Early Age at First Childbirth on Maternal and Infant Health.PMC.2015:259-284.

Gyan, Charles. The Effect of Teenege Pregnancy on the Educational Attainment of Girlas at Chorkor, a Suburb of Accra.Journal of Educational and Social Research MCSER Publishing Rome-Italy.2013:53-60.

Hidayat, Alimul AA.Metode penelitian kebidanan teknik data. Salemba Medika;2007;56-122.

Melina Fitria, Subiyanto, Wujoso Hari.Perbedaan Media Pembelajaran (Leaflet dan Video Terhadap Keterampilan Sadari Ditnjau dari Motivasi.Jurnal Kesehatan “ Samodra Ilmu” Vol. 05 No. 2 Jul 2014.

Notoatmojo S. Pengantar Pendidikan Kesehatan dan Ilmu Perilaku Kesehatan. Andi Offset. Jakarta. 2007.

Nyong, EE, Asuquo SE, Obia EE.Teenage Pragnancy and Education in Nigeria: A Philo-Sociological Management Strategy.Rome-Italy.Journal of Educational and Social Research MCSER Publisging.2014:41-47.

Omarsari, Dwi Sri, Djuwita Ratna.Kehamilan Pranikah Remaja di Kabupaten Sumedang.2008:2-8

Stanger, Hall KF and Hall DW.Abestinence-Only Education and Teen pregnancy Rates: Why We Need Comprehensive Sex Education in the U.S.PMC.2011.

Umairah, Siti. Tingkat Pengetahuan Siswa Putri SMA Tentang Kehamilan Usia Dini Desa Pancasari Kecamatan Sukasada Kabupaten Buleleng Bali 2014. Bali. E-Jurnal Medika Vol.5 No.4, April 2016.

Sugiyono.Statistika Untuk Penelitian. Alfabeta. Bandung. 2010. Hal 120.

Supriadi, dkk. Perbedaan Pengaruh Pendidikan Kesehatan Menggunakan Media Video dan 
Firda Thursyana ${ }^{1}$,Puspa Sari ${ }^{2}$, Merry Wijaya ${ }^{3}$

Perbandingan Pengetahuan Remaja Tentang Dampak Kehamilan Pada Remaja Sebelum Dan.......

Media Modul Terhadap Perubahan WHO. Maternal, newborn, child and adolescent Pengetahuan dan Perilaku Tentang health: Adolescent development;2015. SADARI pada Siswi Kelas XI SMA. http://www.who.int/maternal child adoles Jurnal Husada Mahakam.Vol.3 No.8 Hal cent/topics/adolescence/dev/en/ 319-442. November 2014 
Firda Thursyanal,Puspa Sari2, Merry Wijaya3

Perbandingan Pengetahuan Remaja Tentang Dampak Kehamilan Pada Remaja Sebelum Dan.......

Journal-aipkind.or.id 